\title{
Body Image Perception and Internalization Problems Indicators in Mexican Adolescents
}

\author{
Cecilia Colunga-Rodríguez ${ }^{1,2}$, Mercedes Gabriela Orozco-Solis¹, María Elena Flores-Villavicencio, \\ José María de-la-Roca-Chiapas ${ }^{3}$, Ricardo Gómez-Martínez², Alfonso Mercado4, \\ Julio César Vázquez-Colunga1, Juan Carlos Barrera-de-León², \\ Claudia Liliana Vázquez-Juárez ${ }^{1}$, Mario Ángel-González ${ }^{1,5}$
}

\author{
${ }^{1}$ University Center for Health Sciences, University of Guadalajara, Guadalajara, Mexico \\ IMSS), Guadalajara, Mexico \\ ${ }^{3}$ University of Guanajuato, Guanajuato, Mexico \\ ${ }^{4}$ University of Texas, Río Grande Valley, TX, USA \\ ${ }^{5}$ University Center of Tonala, University of Guadalajara, Guadalajara, Mexico \\ Email:ccolungar@yahoo.com
}

${ }^{2}$ Pediatric Hospital of the National West Medical Center at the Instituto Mexicano del Seguro Social (Mexican Social Security Institute, or

How to cite this paper: Colunga-Rodríguez, C., Orozco-Solis, M. G., Flores-Villavicencio, M. E., de-la-Roca-Chiapas, J. M., GómezMartínez, R., Mercado, A., Vázquez-Colunga, J. C., Barrera-de-León, J. C., Vázquez-Juárez, C. L., \& Ángel-González, M. (2016). Body Image Perception and Internalization Problems Indicators in Mexican Adolescents. Psychology, 7, 1671-1681.

http://dx.doi.org/10.4236/psych.2016.713158

Received: October 20, 2016

Accepted: November 15, 2016

Published: November 18, 2016

Copyright $\odot 2016$ by authors and Scientific Research Publishing Inc. This work is licensed under the Creative Commons Attribution International License (CC BY 4.0).

http://creativecommons.org/licenses/by/4.0/

(c) (i) Open Access

\begin{abstract}
The aim of the study was to determine the existing differences by gender in the indicators of internalizing problems regarding the body image perception of Mexican adolescents. A descriptive and transversal study was developed. The participants were students from four public middle schools in Guadalajara Mexico. The instrument used was an online survey constituted by a sociodemographic section, an internalizing problems indicators scale $(\alpha=.85)$ and a body image perception scale $(\alpha=.70)$. Parental consent was obtained using a waiver of active consent. The survey was applied online, during school hours at the computer labs. Descriptive statistics were calculated for the sociodemographic data and the body perception scale. Zscores were determined for the internalizing problems scale, being categorized into a three level rank. Statistical differences were estimated by gender using one-way analysis of variance (ANOVA). The sample included 2080 adolescents with a mean age of 13.6 years (SD 1), of which 51\% (1059) were female and $49 \%$ (1021) male. $18.1 \%$ of the participants that describe themselves as about the right weight, followed by $13.9 \%$ that do it as slightly overweight, indicating that they are trying to lose weight. Regarding the differences by gender, $16 \%$ of the males and $17.9 \%$ of the females have high indicators of internalizing problems. Taking into consideration the body image, the males that describe themselves as very overweight and the females that do it as very underweight are the groups with higher indicators of internalizing problems. In summary, there are important differences between males and females in the internalizing problems indicators regarding the body image.
\end{abstract}




\section{Keywords}

Body Image, Internalizing Problems, Gender

\section{Introduction}

Adolescence is a transition stage from childhood to adulthood which takes place between the age of 10 and 19 years. It is usually divided in two phases: early adolescence, 10 - 14 years old, and late adolescence, from 15 to 19 years (World Health Organization, 2014). This is an important development stage for the human being, in which intense biological and psychosocial changes are experience (Lima, Ferrer, Fernández, \& González, 2012; Iglesias, 2013). At a biological level, the adolescent experiences important hormonal modifications, which mainly cause physical growth acceleration and the development of the secondary sex characteristics (Aliño, López, \& Navarro, 2006). The hormonal changes have a strong association with the psychosocial modifications experience during adolescence; however, the individual personality traits and the social group characteristics will play an important role in the adolescent psychosocial changes, which in general involve the search for independence, the need for social acceptance by the peers, the identity development, and the beginning of the preoccupation for the body image (Lima, Ferrer, Fernández, \& González, 2012; Iglesias, 2013).

The body image is defined as a construct that comprises the body perceptions (perceptive component); attitudes, feelings and thoughts (cognitive-affective component); and the behaviors generated from these components (Baile, 2003; Fernández, González, Contreras, \& Cuevas, 2015). This set of elements contributes to the construction of the individual self-concept. In the complex process of the development of the body image, the esthetic model imposed by society generates an unavoidable comparison between the actual body figure and the ideal image, which usually generates feelings of dissatisfaction, especially during adolescence, because in this stage, the body is constantly changing in a process accompanied by the growing need of obtain approval from the peers, where the perception of the adolescent's body becomes fundamental at the time of interacting with others (Fernández, González, Contreras, \& Cuevas, 2015).

When the adolescent has a negative perception of the body image, the presence of psychosocial alterations increases, being the most usual the eating disorders and low self-esteem (Griffoulière, Rivarola, Galarsi, \& Penna, 2013; Tiunova, 2015; Pedro, Micklesfield, Kahn, Tollman, Pettifor, \& Norris, 2016). Also, the studies report that a negative body image is associated with the generation of internalizing problems, such as depression and anxiety (Almeida, Severo, Araújo, Lopes, \& Ramos, 2012; Lee, 2012; Herazo \& Villamil, 2013); which are relevant problems during adolescence, because they can remain present until adulthood, being associated with important phenomenon's such as suicide, substance use, bullying, school dropout, etc. (Pérez, Rivera, Atienzo, de Castro, Leyva, \& Chávez, 2010; Manrique, Ospina, \& Garcia, 2011; Cubillas, Román, Valdez, \& Galaviz, 2012; Holubcikova, Kolarcik, Madarasova, Van Dijk, \& 
Reijneveld, 2015).

Most of the studies aimed to analyze the association between body image and internalizing problems had been conducted in developed countries, being scarce the research develop about this topic in our context. In Mexico, most of the research focuses on the discrepancies between the Body Mass Index and the body image in adolescents (Sámano et al., 2015; Oliva, Ordóñez, Santana, Marín, Andueza, \& Gómez, 2016); however, little is known about the difference in the internalizing problems indicators between those adolescents with a positive body image and those without, especially regarding the adolescent's gender, a factor considered relevant in this topic by several studies (Hagger, Stevenson, Chatzisarantis, Pereira, Leitão, \& González, 2010; Almeida, Severo, Araújo, Lopes, \& Ramos, 2012; Holubcikova, Kolarcik, Madarasova, Van Dijk, \& Reijneveld, 2015). Because of this lack of information, the aim of this study was to determine the existing differences by gender in the indicators of internalizing problems regarding the body image perception of Mexican adolescents.

\section{Research Setting}

The study was developed in Guadalajara and Tlaquepaque, two cities from the center area of Jalisco, Mexico. In our country, the school system is divided in kindergarten, elementary, middle school, high school and college. The research was conducted in public middle schools, educational level that consist of three grades, attended by the students when they are 12 to 15 years old.

\section{Methodology}

\subsection{Participants}

The research participants were middle school students. A list of public middle schools that met the criteria of having functional computer labs equipped with internet access was obtained. Four schools were selected randomly for the survey application. All the students present at the moment of the data collection were included in the sample if they met the requirement of being enrolled regularly in the school and have no difficulty in handling the computer by themselves.

\subsection{Instrument}

The participants answer an online survey constituted by a sociodemographic section, that gather data about: gender, age, mother school level, school grade and school shift attended. The next section included an internalizing problem indicator scale, constituted by nine questions destined to ask about the frequency in which the adolescent has experience internalizing problems related with anxiety, depression and impulse control; the answer options were in a four-point Liker Scale, going from never to almost always. The final part of the survey was the body image perception scale, composed by two questions, the first one related to the self-description of the participant's current weight, having five answer options: very underweight, slightly underweight, about the right weight, slightly overweight and very overweight; the second item asked about if 
the adolescent was trying to do something with its weight, with four answer options: lose weight, gain weight, stay the same weight and I am not trying to do anything about my weight.

Cronbach's Alpha was calculated for the survey sections, obtaining a score of .8 for the internalizing problems scale and .70 for the body image perception scale.

\subsection{Data Collection}

The parental consent was obtained through a waiver of active parental consent. A document that contained the research aims, procedures and ethical aspects was sent to the parents, stablishing that the student's participation would be voluntary and confidential. The form instructed the parents to return it signed to the school administration. The schools took note of the parents that denied the students participation, proceeding to excluded them from the research

The survey was applied by the researchers' team in the school's computer labs. One session lasting 20 minutes was necessary for the students to answer the survey. At the beginning of the session, the procedures, aims and ethical considerations were explained to the participants, clarifying that their participation in the research will be voluntary and confidential at all moments, mentioning that it would be no consequences if they denied to participate or abandon the survey application. After the student's doubts were clear, the instructions to answer the survey were read aloud, instructing the participants to enter the survey site and use a password created for each school to enter the survey section. When the students finished answering the survey, they returned to their classrooms, without receiving any material or scholar gratification.

\subsection{Data Analysis}

A database was created and analyzed with SPSS version 20.0 program. Descriptive statistics were calculated for the sociodemographic data and the body perception scale. $\mathrm{Z}$-scores were determined for the internalizing problems scale; the Z-scores were categorized into a three level rank, taking as low, the values lower than plus 2 standard deviation (SD); as medium, the scores between plus 2 SD and plus 4 SD; and high, for the values higher than plus $4 \mathrm{SD}$. The statistical differences existing in the internalizing problems indictors based in the body image perception were estimated by gender using one-way analysis of variance (ANOVA).

\subsection{Ethic Considerations}

The procedures for the development of the research were reviewed and approved by the Ethics Committee Review Board of the Inter institutional Doctorate in Psychology at the University of Guadalajara.

\section{Results}

\subsection{Sociodemographic Characteristics}

A total of 2080 students participated in the research. Mean age was 13.6 years (SD 1), 
$51 \%$ (1059) were female and 49\% (1021) male. The mother school level is presented in Table 1.

The school variables distribution (school grade and shift), indicated that a higher number of students were attending school in the first grade and at the morning shift (Table 2).

\subsection{Body Image Perception}

The items from the body image perception scale were analyzed using frequencies and percentages. The results indicate that the adolescents that describe their weight as about the right weight and slightly overweight, are the ones that referred to try to lose weight more frequently (Table 3).

Table 1. Student's mothers school level.

\begin{tabular}{ccc}
\hline School level & $\mathrm{n}$ & $\%$ \\
\hline Did not finished high school & 1376 & 66.1 \\
Finished high school & 467 & 22.4 \\
When to college, but did not graduate & 109 & 5.2 \\
Graduated from college & 128 & 6.1 \\
\hline
\end{tabular}

$\mathrm{n}=$ frequency, sample $=2080$.

Table 2. Student's school grade and school shift.

\begin{tabular}{|c|c|c|c|c|c|}
\hline & & \multicolumn{4}{|c|}{ School Shift } \\
\hline & & \multicolumn{2}{|c|}{ Morning shift } & \multicolumn{2}{|c|}{ Afternoon shift } \\
\hline & & $\mathrm{n}$ & $\%$ & $\mathrm{n}$ & $\%$ \\
\hline \multirow[t]{3}{*}{ School grade } & First grade & 400 & 19.2 & 355 & 17 \\
\hline & Second grade & 379 & 18.2 & 376 & 18 \\
\hline & Third grade & 345 & 16.5 & 225 & 10.8 \\
\hline
\end{tabular}

$\mathrm{n}=$ frequency, sample $=2080$.

Table 3. Weight perception and intentions about the current weight referred by the participants.

\begin{tabular}{|c|c|c|c|c|c|c|c|c|}
\hline \multirow{3}{*}{ Weight self-description } & \multicolumn{8}{|c|}{ Intentions about weight } \\
\hline & \multicolumn{2}{|c|}{ Lose weight } & \multicolumn{2}{|c|}{ Gain weight } & \multicolumn{2}{|c|}{$\begin{array}{c}\text { Stay the same } \\
\text { weight }\end{array}$} & \multicolumn{2}{|c|}{$\begin{array}{l}\text { I am not trying } \\
\text { to do anything } \\
\text { about my weight }\end{array}$} \\
\hline & $\mathrm{n}$ & $\%$ & $\mathrm{n}$ & $\%$ & $\mathrm{n}$ & $\%$ & $\mathrm{n}$ & $\%$ \\
\hline Very underweight & 63 & 3 & 64 & 3 & 34 & 1.6 & 16 & .7 \\
\hline Slightly underweight & 83 & 3.9 & 113 & 5.4 & 57 & 2.7 & 32 & 1.5 \\
\hline About the right weight & 378 & 18.1 & 198 & 9.5 & 432 & 20.7 & 133 & 6.3 \\
\hline Slightly overweight & 291 & 13.9 & 9 & .4 & 30 & 1.4 & 15 & .7 \\
\hline Very overweight & 94 & 4.5 & 10 & .4 & 11 & .5 & 17 & .8 \\
\hline
\end{tabular}

$\mathrm{n}=$ frequency, sample $=2080$. 


\subsection{Internalizing Problem Indicators}

The total score from the internalizing problems scale was categorized by gender into three levels using the Z-scores. It is noteworthy that for both gender, a percentage higher than $10 \%$ of the participants score in the high rank of the categorization, corresponding to the group of students that could be having high indicators of internalizing problems (Table 4).

\subsection{Internalizing Problems Indicators Differences by Body Image Perception}

One-way analysis of variance (ANOVA) was used to determine the statistical differences existing by gender in the internalizing problems indicators based in the adolescent body image perception.

Statistically significant differences were observed between the groups for both gender $(<.01)$. The data points out that the females tend to have higher internalizing problem indicators in all the weight perception groups. The differences by gender were, for the males, between those students that perceived their body image as very overweight and those that describe themselves as around the right weight, and for the females, between the adolescents with a very underweight body perception and those that describe themselves as around the right weight (Table 5).

Regarding the intentions about weight, no statistically significant differences were found by gender for the internalizing problems indicators (Table 6).

Table 4. Prevalence of internalizing problem indicators in middle school students.

\begin{tabular}{ccccccccc}
\hline & & \multicolumn{5}{c}{ Levels of distribution } \\
\cline { 3 - 8 } & Gender & & \multicolumn{2}{c}{ Low } & & Medium & High \\
\cline { 3 - 8 } & & $\mathrm{n}$ & $\%$ & $\mathrm{n}$ & $\%$ & $\mathrm{n}$ & $\%$ \\
\hline $\begin{array}{c}\text { Internalizing problem } \\
\text { indicators }\end{array}$ & Male & 195 & 19.1 & 663 & 64.9 & 163 & 16 \\
& Female & 135 & 12.7 & 734 & 69.3 & 190 & 17.9 \\
\hline
\end{tabular}

$\mathrm{n}=$ frequency, sample $=2080$.

Table 5. Internalizing problem indicators compared based of the student's weight perception.

\begin{tabular}{cccccccccc}
\hline & & \multicolumn{7}{c}{ Weight perception } \\
\cline { 3 - 9 } & & Mender & VU & SU & ARW & SO & VO & F & $p$ \\
\cline { 3 - 9 } & Male & $2.07 \pm .66$ & $2.06 \pm .60$ & $1.91 \pm .56$ & $1.96 \pm .59$ & $2.18 \pm .61^{* * *}$ & 4.96 & .001 \\
\hline $\begin{array}{c}\text { Internalizing } \\
\text { problems } \\
\text { indicators }\end{array}$ & Female & $2.24 \pm .50^{* * *}$ & $2.05 \pm .58$ & $2.01 \pm .5$ & $2.07 \pm .54$ & $2.17 \pm .61$ & 4.17 & .002 \\
\hline
\end{tabular}

Note: VU, very underweight; SU, slightly underweight; ARW, about the right weight; SO, slightly overweight; VO, very overweight. ${ }^{*} p<.05$ compared with very underweight group. ${ }^{* *} p<.05$ compared with slightly underweight group. ${ }^{* * *} p<.05$ compared with about the right weight group. ${ }^{* * *} p<.05$ compared very overweight group. 
Table 6. Internalizing problem indicators compared based of the student's intentions about weight.

\begin{tabular}{|c|c|c|c|c|c|c|c|}
\hline & \multirow[b]{3}{*}{ Gender } & \multicolumn{6}{|c|}{ Intentions about weight } \\
\hline & & \multicolumn{4}{|c|}{ Mean \pm SD } & \multirow[b]{2}{*}{$\mathrm{F}$} & \multirow[b]{2}{*}{$p$} \\
\hline & & $\begin{array}{c}\text { Lose } \\
\text { weight }\end{array}$ & $\begin{array}{c}\text { Gain } \\
\text { weight }\end{array}$ & $\begin{array}{c}\text { Stay the } \\
\text { same weight }\end{array}$ & $\begin{array}{l}\text { I am not } \\
\text { trying to do } \\
\text { anything } \\
\text { about my } \\
\text { weight }\end{array}$ & & \\
\hline $\begin{array}{l}\text { Internalizing } \\
\text { problems }\end{array}$ & Male & $1.99 \pm .60$ & $1.99 \pm .62$ & $1.90 \pm .60$ & $1.93 \pm .58$ & 1.22 & .299 \\
\hline indicators & Female & $2.09 \pm .56$ & $2.07 \pm .53$ & $1.98 \pm .59$ & $1.99 \pm .51$ & 2.44 & .062 \\
\hline
\end{tabular}

\section{Discussion}

The aim of the study was to determine the existing differences by gender in the indicators of internalizing problems regarding the body image perception of Mexican adolescents. The most relevant findings were that only a small percentage of the participants described their weight as normal and do not intent to do anything about it; regarding the differences by gender, the females tend to have slightly higher indicators of internalizing problems, difference that remains present when we take into consideration the body image perception.

Weight perception is an important part of the body image, because it reflexes the results from the comparison made between the ideal body and the perceived body. In our research we observed that only a small part of the participants, less than $30 \%$, feels satisfied with their body weight, indicating that they are near the normal weight and that they are not trying to do anything about it. This finding differs from the mentioned by a study developed in Mexico City with 330 adolescents, in which $80 \%$ of the participants reported to feel satisfied with its body perception, this significant difference could be explain by the instrument used, the characteristics of the population and because of the difference in the adolescents age, given that the mean age of the participants of the other research was $16 \pm 2$ years old, points that need to be taken into consideration for the development of future research (Sámano et al., 2015).

Regarding the feelings of dissatisfaction towards the weight perception, we found that the adolescents that describe themselves as about the right weight and slightly overweight are the ones referring to be trying to do something to lose weight more frequently, we could say, they might be the most unsatisfied with their bodies, result that agrees with the mentioned by other studies that point out that the adolescents with higher weight tend to be more unsatisfied and therefore to apply more dietary restrictions aiming to lose weight (Goldfield, Moore, Henderson, Buchholz, Obeid, \& Flament, 2010). However, other research has also found that a high number of the adolescents that perceive themselves as normal weigh are also currently trying to lose weight, result probably explained for the existing preference for thinness as an indicator of 
beauty, more significantly present in the Western culture, expectation that could play an important role in the development of internalizing problems among the adolescents, when the ideal body does not match with the perceive one (Almeida, Severo, Araújo, Lopes, \& Ramos, 2012).

The internalizing problems are a commonly find alteration among adolescents, because in this stage is common to observed that when the individual does not adapt, develops or fulfill its needs successfully, such problems could appear easily, either alone or accompanied by other alterations such as the behavioral (Wang \& Dishion, 2011; Rawal et al., 2014). This idea is supported by our research findings that indicate that a percentage higher than $10 \%$ of the participant have high indicators if internalizing problems, result that needs to be taking into consideration for the development of future research and intervention strategies focus to reduce these indicators during adolescence, in order to prevent the generation of more serious alterations that could remain present until adulthood (Manrique, Ospina, \& Garcia, 2011; Cubillas, Román, Valdez, \& Galaviz, 2012; Holubcikova, Kolarcik, Madarasova, Van Dijk, \& Reijneveld, 2015). There are reports that indicate the existence of difference by gender in the prevalence of this type of problems, where the females tend to have higher indicators of its presence compare to the males, results supported by the findings of this research that point out that the females tend to have slightly higher indicators of internalizing problems, probably because of the personality traits and the social patterns stablished for each gender (Hagger, Stevenson, Chatzisarantis, Pereira, Leitâo, \& González, 2010; Van Oort et al., 2011; Strömbäck, Wiklund, Salander, \& Malmgren, 2015).

The body image and the internalizing problems are aspects strongly linked, especially during adolescence, where the main preoccupation is to obtain peers acceptance, process in which the body image plays an important role, influencing in the characteristics of the social interactions. However, when the adolescent is not satisfied with its body image, it is common to observe the development of problems such as the internalizing type. In this aspect, there are studies that describe the existence of important differences in the way the adolescent experience this process by gender, agreeing with the results obtained from our research, that indicate that the females with body image dissatisfactions tend to have higher indicators of internalizing problems than the males (Hagger, Stevenson, Chatzisarantis, Pereira, Leitâo, \& González, 2010; Waghachavare, Quraishi, Dhumale, \& Gore, 2014).

Statistically significant differences in the indicators of internalizing problems regarding the body image perception were observed by gender. The results indicated that the males that describe themselves as very overweight presented the higher indicators of internalizing problems, while for the females, the girls that perceive themselves as very underweight had the higher indicators. The differences found in our research are consistent with the results from several studies that point out that the males have higher probabilities to develop internalizing problems, such as depression, when they perceive themselves as overweight or obese, body image perceptions that result more significant for the boys (Schiefelbein, Mirchandani, George, Becker, Castrucci, \& Huelscher, 2012; 
Oliva, Ordóñez, Santana, Marín, Andueza, \& Gómez, 2016). In the female case, most of the studies report that the overweight and obese girls tend to have higher indicators of internalizing problems, because of the discrepancy between the ideal body weight and the adolescent perception, however, other studies also mention that the females tend to dislike the obesity but also the underweight, reporting that one of each five females want to have a bigger figures, not necessarily obese, but more voluptuous (Almeida, Severo, Araújo, Lopes, \& Ramos, 2012; Oliva, Ordóñez, Santana, Marín, Andueza, \& Gómez, 2016).

Finally, it is necessary to point out that no statistically significant differences by gender were observed for the internalizing problems indicators regarding the intentions about weight, indicating that this variable might not be a factor that makes a difference in the development of internalizing problems, where the adolescent's perception about its body could be playing a more important role in the generation of this type of alterations.

The research limitations are that only schooled adolescents were included, being necessary to develop future research that includes other groups of adolescents in order to be able to stablish if there are differences between them. Methodologically, it would be important to include other body image surveys that incorporate information about feelings and beliefs in future studies. Also, considering that the results obtained from this study have a descriptive level, it is necessary to develop other researches that extend to an association, correlation and predictive level. Despite these limitations, the findings obtained from this study represent an important input about relevant topics for adolescents, such as body image and internalizing problems indicators, which needs to be taken into consideration for the development of other researches that promote the generation of more effective prevention strategies that could favor the adolescent healthy development.

\section{Conclusion}

In summary, we were able to observe that only a small part of the adolescents felt satisfied with their body image, finding that the participants that described their weight as normal and slightly overweight were the ones trying to lose weight more frequently. About the internalizing problems indicators, the females tended to have higher levels than the males. Regarding the differences by gender in the internalizing problems indicators based in the body image perception, the findings indicate that the boys that describe themselves as very overweight and the girls that perceive themselves as very underweight were the groups that presented higher indicators of internalizing problems.

\section{Acknowledgements}

To the University of Guadalajara, the Secretaria de Educación Jalisco (Jalisco Ministry of Education SEJ) and the Consejo Nacional de Ciencia y Tecnología (National Science and Technology Council CONACyT) for the support provided for the development this study. And also to the participants who took part in this research 


\section{Conflict of Interest Declaration}

The authors declare that there is no conflict of interests with the development of the study, the authorship and/or the publication of this paper.

\section{References}

Aliño, M., López, J., \& Navarro, R. (2006). Adolescence. General Aspects and Health Care. Revista Cubana de Medicina General Integral, 22.

Almeida, S., Severo, M., Araújo, J., Lopes, C., \& Ramos, E. (2012). Body Image and Depressive Symptoms in 13-Year-Old Adolescents. Journal of Pediatrics and Child Health, 48, E165-E171. http://dx.doi.org/10.1111/j.1440-1754.2012.02576.x

Baile, J. I. (2003). What Is the Body Image? Cuadernos del Marqués de San Adrián. Revista de humanidades, 2, 53-70.

Cubillas, M., Román, R., Abril, E., \& Galaviz, A. (2012). Depression and Suicidal Behavior in Senior High School Students in Sonora. Salud Mental, 35, 45-50.

Fernández, J., González, I., Contreras, O., \& Cuevas, R. (2015). Relationship between Body Image and Physical Self-Concept in Adolescent Females. Revista Latinoamericana de Psicología, 47, 25-33.

Goldfield, G., Moore, C., Henderson, K., Buchholz, A., Obeid, N., \& Flament, M. (2010). Body Dissatisfaction, Dietary Restraint, Depression, and Weight Status in Adolescents. Journal of School Health, 80, 186-192. http://dx.doi.org/10.1111/j.1746-1561.2009.00485.x

Griffoulière, M., Rivarola, M., Galarsi, M., \& Penna, F. (2013). Body Image and Coping Strategies in School-Age Adolescents from the City of San Luis. Fundamentos en Humanidades, 14, 95 117.

Hagger, M., Stevenson, A., Chatzisarantis, N., Pereira, P., Leitão, J., \& González, J. (2010). Physical Self-Concept and Social Physique Anxiety: Invariance across Culture, Gender and Age. Stress and Health, 26, 304-329. http://dx.doi.org/10.1002/smi.1299

Herazo, E., \& Villamil, M. (2013). Relationship among Depressive Symptoms, Body Mass Index and Self-Perception of Weight in Adolescents. Salud Uninorte, 29, 368-373.

Holubcikova, J., Kolarcik, P., Madarasova, A., Van Dijk, J., \& Reijneveld, S. (2015). Is Subjective Perception of Negative Body Image among Adolescents Associated with Bullying? European Journal of Pediatrics, 174, 1035-1041. http://dx.doi.org/10.1007/s00431-015-2507-7

Iglesias, J. (2013). Adolescent Development: Physical, Psychological and Social Aspects. Pediatría Integral, 17, 88-93.

Lee, J. (2012). The Relationship between Appearance-Related Stress and Internalizing Problems in South Korean Adolescent Girls. Social Behavior and Personality, 40, 903-918.

Lima, Y., Ferrer, A., Fernández, C., \& González, P. (2012). The Excess Weight in Adolescents and Its Relation to Some Sociodemographic Factors. Revista Cubana de Medicina General Integral, 28, 26-33.

Manrique, F., Ospina, J., \& Garcia, J. (2011). Children and Adolescents' Alcohol and Tobacco Consumption in Tunja, Colombia, 2009. Revista de Salud Pública, 13, 89-101. http://dx.doi.org/10.1590/S0124-00642011000100008

Oliva, Y., Ordóñez, M., Santana, A., Marín, A., Andueza, G., \& Gómez, I. (2016). Concordance of the Body Mass Index and the Perception of Body Image in Adolescents in Yucatán. Revista Biomédica, 27, 49-60.

Pedro, T., Micklesfield, L., Kahn, K., Tollman S., Pettifor, J., \& Norris, S. (2016). Body Image Sa- 
tisfaction, Eating Attitudes and Perceptions of Female Body Silhouettes in Rural South African Adolescents. PLOS ONE, 11, e0154784.

http://journals.plos.org/plosone/article?id=10.1371\%2Fjournal.pone.0154784

http://dx.doi.org/10.1371/journal.pone.0154784

Pérez, B., Rivera, L., Atienzo, E., de Castro, F., Leyva, A., \& Chávez, R. (2010). Prevalence and Associated Factors to the Suicidal Ideation and Intent in Adolescent Students in Mexico. Salud Pública de México, 52, 324-333.

Rawal, A., Riglin, L., Ng-Knight, T., Collishaw, S., Thapar, A., \& Rice, F. (2014). A Longitudinal High-Risk Study of Adolescent Anxiety, Depression and Parent-Severity on the Developmental Course of Risk-Adjustment. Journal of Child Psychology and Psychiatry, 55, 1270-1278. http://dx.doi.org/10.1111/jcpp.12279

Sámano, R., Rodríguez, A., Sánchez, B., Godínez, E., Noriega, A., Zelonka, R., Garza, M., \& Nieto, J. (2015). Body Image Satisfaction in Mexican Adolescents and Adults and Its Relation with Body Selfperception and Real Body Mass Index. Nutrición Hospitalaria, 31, 1082-1088.

Schiefelbein, E., Mirchandani, G., George, G., Becker, E., Castrucci, B., \& Hoelscher, D. (2012). Association between Depressed Mood and Perceived Weight in Middle and High School Age Students: Texas 2004-2005. Maternal and Child Health Journal, 16, 169-176.

http://dx.doi.org/10.1007/s10995-010-0733-1

Strömbäck, M., Wiklund, M., Salander, E., \& Malmgren, E. (2015). Complex Symptomatology among Young Women Who Present with Stress-Related Problems. Scandinavian Journal of Caring Sciences, 29, 234-247. http://dx.doi.org/10.1111/scs.12154

Tiunova, A. (2015). Relationship of Body Image and Selfesteem in Adolescents with Different Types of Constitutional Development: Preliminary Results. Activitas Nervosa Superior, 87, 8186.

Van Oort, F., Greaves-Lord, K., Ormel, J., Verhulst, F., \& Huizink, A. (2011). Risk Indicators of Anxiety throughout Adolescence: The TRAILS Study. Depression and Anxiety, 28, 485-494. http://dx.doi.org/10.1002/da.20818

Waghachavare, D., Quraishi, S., Dhumale, G., \& Gore, A. (2014). A Cross-Sectional Study of Correlation of Body Image Anxiety with Social Phobia and Their Association with Depression in the Adolescents from a Rural Area of Sangli District in India. International Journal of Preventive Medicine, 5, 1626-1629.

Wang, M., \& Dishion, T. (2011). The Trajectories of Adolescents' Perceptions of School Climate, Deviant Peer Affiliation, and Behavioral Problems during the Middle School Years. Journal of Research on Adolescence, 22, 40-53. http://dx.doi.org/10.1111/j.1532-7795.2011.00763.x 
Submit or recommend next manuscript to SCIRP and we will provide best service for you:

Accepting pre-submission inquiries through Email, Facebook, LinkedIn, Twitter, etc. A wide selection of journals (inclusive of 9 subjects, more than 200 journals)

Providing 24-hour high-quality service

User-friendly online submission system

Fair and swift peer-review system

Efficient typesetting and proofreading procedure

Display of the result of downloads and visits, as well as the number of cited articles

Maximum dissemination of your research work

Submit your manuscript at: http://papersubmission.scirp.org/

Or contact psych@scirp.org 